\title{
O serviço de saúde antirracista: instrumentos de dessilenciamento racial e o ensino-serviço médico libertador
}

\author{
George Luiz Neris Caetano ${ }^{1}$ \\ Daniela Sousa de Oliveira ${ }^{2}$ \\ Priscila Katleen Rodrigues de Oliveira Carvalho ${ }^{3}$ \\ Diane Maria Scherer Kuhn Lago ${ }^{4}$ \\ Sônia Maria Roseno 5
}

RESUMO: Este trabalho objetiva a compreensão dos efeitos de ações antirracistas na formação/prática médica, mediante interação com atores e cenários populares assistidos por serviços de saúde em uma zona rural do estado de Minas Gerais. Dada a partilha dos saberes e inclusão do conhecimento popular, busca-se fomentar a reflexão crítica e possibilitar a construção coletiva de mudanças antirracistas no fazer médico. A criação e oferta da matéria optativa denominada "Instrumentos da Medicina Antirracista", para graduandos em medicina e residentes de clínica médica apresenta-se como resposta às práticas racistas e ao silenciamento étnico racial. Para o resgate epistemológico da oralidade, as abordagens giraram no sentido do campo epistêmico pós-estruturalista e etnográfico, alinhando ações, teorias e práticas antirracistas na formação médica inicial e continuada, abrangendo o campo do ensino-serviço com a narrativa teórico-prática. Os resultados obtidos das intervenções realizadas reforçam a necessidade de ampliação de intervenções curriculares e a readequação da educação-serviço, transformando-a em instrumento contra as desigualdades sociais e favorecendo o desenvolvimento identitário.

PALAVRAS-CHAVE: Antirracismo; Dessilenciamento; Étnico Racial; Formação e Prática Médica.

\footnotetext{
${ }^{1}$ Acadêmico de Medicina na FM/UnB. Pedagogo na FE/UEMG.

2 Terapeuta Ocupacional Residente do Programa de Saúde Mental do Adulto ESCS/ FEPECS. Mestranda do Programa de Pós-Graduação de Saúde Coletiva - UnB.

${ }^{3}$ Acadêmica de Medicina na FM/UnB. Bacharel em Física na FIS/UnB.

${ }^{4}$ Doutora em Enfermagem e Professora Adjunta na Universidade de Brasília.

${ }^{5}$ Pós-Doutoranda na Universidade Estadual Paulistana. Doutora em Educação na UFMG.
} 


\section{The anti-racist health service: instruments of racial desiliation and liberating medical teaching-service}

ABSTRACT: This study has the objective of understanding the effect of anti-racist actions during the training years and practice of doctors, through interactions with people from a poverty and rural area in the state of Minas Gerais who were attended by public health care. Through knowledge sharing and the inclusion of popular knowledge and wisdom, it seeks to create a critical reflection and make anti-racist politics possible in the medical activitiy. The creation of an optative discipline for medical students during graduation and for medical clinic residentes shows itself as a good answer against racism and racial-ethnic silence. For the epistemological rescue of orality, the approaches turned towards the post-structuralist and ethnographic epistemic field, aligning anti-racist actions, theories and practices in initial and continuing medical training, covering the field of teaching-service with the theoretical-practical narrative The results of the interventions made reinforce the need of a greater curricular change to accommodate the racial issue and also the readjustment of the educational service provided to the community, transforming it in an instrument against social inequality and favouring the development of the identity of racial minorities.

KEY WORDS - Anti-racism; Medical training; Racial-ethnicity; Unsilencing.

\section{INTRODUÇÃO}

Historicamente inúmeros povos, como o povo preto, os povos indígenas e vários outros cujos sistemas sociopolítico e socioeconômico estruturam-se na oralidade e na lógica antiantropocêntrica, passaram por processos de silenciamento ${ }^{3}$. Trata-se de um atentado contra o multiculturalismo, importante para as relações sociais desde o primórdio dos tempos, sendo esse um ataque contra a busca de igualdade entre os grupos raciais e as nuances culturais ${ }^{3-4}$ que estes possam expressar no cerne da construção de laços sociais coletivos.

Tendo por finalidade destacar a importância da formação/prática antirracista na medicina $^{12}$, utilizando e promovendo instrumentos dessilenciadores, aqueles capazes de perceber as práticas antirracistas como agentes ativas na construção epistemológica na defesa 
de narrativas multirraciais ${ }^{12-15}$. As Práticas Integrativas Complementares em Saúde (PICS) ${ }^{2}$, aliadas a outras ações interventivas multidisciplinares, como a Pedagogia Griô ${ }^{23}$, permitem acesso aos possíveis instrumentos dessilenciadores aqui utilizados. Logo, este trabalho pretende discutir a estrutura eurocentrista e hegemônica que inibem a formação/prática médica antirracista $^{1-7,27}$.

Empobrecer o debate sobre racismo é por si uma prática racista ${ }^{5,15}$, pois tenta tornar irrelevante um diálogo negado por décadas na formação/prática médica. Por esta razão, este trabalho está divido em desdobramentos ${ }^{8}$ que buscam fomentar a reflexão crítica e possibilitar a construção coletiva de mudanças antirracistas não só na formação, mas também na prática médica.

O conceito de raça permanece sem um consenso homogêneo ${ }^{12,27}$, abrindo margem para discussões empobrecidas e discursos unilaterais que continuam a favorecer apenas determinada ideologia racial, como é o caso da falsa democracia racial, debatida no tópico desconstruindo a democracia racial.

A desconstrução do mito da democracia racial, inicialmente desenhada pelo sociólogo Gilberto Freyre, autor do livro Casa-Grande e Senzala (1933), aponta para o debate crítico acerca das micro e macro violências que os povos não hegemônicos vem sofrendo no decorrer nos séculos, servindo, assim, como ponte para outras reflexões pontuais, como as que envolvem a problemática da memória, da oralidade e da ancestralidade. Nisto, percebe-se que há um agente construindo e narrando a memória dos povos em processo de dessilenciamento ${ }^{3,18,23}$ e identificá-lo auxiliará no apontamento dos fatores que reforçam a necessidade de dessilenciamento racial, conforme apresentado no decorrer do texto.

Deslegitimando os aspectos culturais, linguísticos e sociopolíticos do povo em dessilenciamento $^{17,32}$, o grupo hegemônico usa variados aspectos do racismo, do preconceito e 
da discriminação na formação/prática médica para isolar e silenciar os grupos étnico raciais, utilizando mecanismos de demonização e inferiorização dos traços e aspectos sociorreligiosos e culturais dos sistemas de crenças não judaico-cristãs, desuso das práticas medicinais tradicionais, que consecutivamente acarreta prejuízo epistêmico na construção identitária destes $\operatorname{povos}^{12-19}$. Assim, é preciso entender qual a posição da medicina diante desses aspectos perversos, como o racismo estrutural e institucionalizado, a intolerância religiosa e segregação/marginalização racial, tema que também será abordado, e apontar nortes para a institucionalização de um currículo antirracista.

A presente discussão resulta na formação e na prática médica antirracista, capaz de auxiliar no dessilenciamento e resgate da memória identitária, norteando, assim, a discussão acerca da medicina complementar informal-popular e multirracial, usada como estratégia intervencionista na formação e na prática médica e nos serviços de saúde em uma zona rural mineira.

\section{JUSTIFICATIVA}

Este resumo busca relacionar formação/prática médica ao dessilenciamento étnico racial, dado o cenário sócio-político do Brasil nos últimos $5 \operatorname{anos}^{30}$, além dos avanços de ideologias e discursos que necessitam de respostas antirracistas.

Dessa maneira o resgate da oralidade e da memória identitária, refletindo acerca da memória comunal no cerne epistemológico racial ${ }^{31}$, buscando novas praxes clínicas, eruditando a tradição oral e os saberes ancestres ${ }^{9,14,33}$, apresenta-se como uma das maneiras de resistência antirracista dentro do cenário acadêmico e da e da relação médico-paciente, dentro do contexto biomédico.

Falar sobre práticas antirracistas consiste na promoção de igualdade sócio racial em um espaço composto majoritariamente por um grupo etnocêntrico. A educação médica, seja a 
inicial ou continuada, bem como a prática clínica, exige o diálogo interracial e multicultural, em resposta às demandas sociais universais, além dos dispositivos jurídicos, como o Estatuto da Igualdade Racial, que preconizam a construção e manutenção de uma sociedade antirracista. Tal exigência não vem sendo cumprida pelas instituições formadoras, de acordo com apontamentos históricos ${ }^{13}$ e estudos sobre as relações raciais ${ }^{3-7}$ no Brasil, construindo lacunas cada vez mais significativas entre as demandas sociais e os cenários da saúde s7-33. $^{27}$.

Dessa forma, promover o debate, a reflexão e análise de questões antirracistas respondem aos contínuos questionamentos sociais acerca do papel da medicina no agravamento da desigualdade sócio racial no País. Assim, identidades silenciadas passam a figurar nos cenários antirracistas como dessilenciadas por ações e intervenções multifatoriais e de interesse coletivo, promovendo saúde, igualdade e reduzindo vulnerabilidades socioeconômicas ${ }^{12,17-18}$.

A medicina base em evidências apresenta um saldo negativo com os povos originários, indígenas, negros e tradicionais, ciganos, quilombolas e ribeirinhos, e tantos outros que foram afetados pelas práticas elitistas, eurocêntricas e racistas da mercantilização da saúde, este trabalho é a busca por equidade, reparação e disseminação de ações combativas ao racismo, atuando nos dois principais eixos da carreira médica: formação e prática clínica ${ }^{28}$.

Por décadas a formação/prática médica corroborou para o processo higienista em curso no Brasil ${ }^{29,30}$. Diversos crimes contra a humanidade foram sustentados por teorias defendidas ou criadas pela medicina ${ }^{21}$, como foi o caso do etnocentrismo, que elevou falsamente o povo branco ao patamar de raça superior e financiou séculos de escravidão e o surgimento de regimes totalitários, como o nazismo alemão.

Portanto, a temática abordada e brevemente detalhada tende à complementação curricular dos cursos de saúde, em especial o de medicina, e pretende integrar o conhecimento 
formal ao informal/popular ${ }^{4,31-32}$, para que práticas complementares do fazer e saber médico antirracista possam partilhar o espaço de fala na construção da ciência médica.

\section{METODOLOGIA}

O trabalho realizado está alicerçado no tripé oralidade-escrita-prática ${ }^{10}$. As metodologias de trabalho buscaram a valorização dos povos não etnocêntricos, como os povo preto, os povos indígenas e tantos outros povos tradicionais originários, e dos seus respectivos descendentes, problematizando os saberes orais e os saberes escritos, ressignificando os lugares políticos e apresentando o saber oral, enquanto ciência que possui uma didática própria e exclusiva no processo de ensino e aprendizagem.

Para o resgate epistemológico da oralidade, as abordagens giraram no sentido do campo epistêmico pós-estruturalista e etnográfico ${ }^{10-11}$, alinhando ações, teorias e práticas antirracistas na formação médica inicial e continuada, abrangendo o campo do ensino-serviço.

O resgate epistemológico foi possível com o planejamento e oferta de uma disciplina ${ }^{9}$ optativa, denominada "Instrumentos da Medicina Antirracista", para graduandos do décimo semestre do curso de medicina e para residentes em clínica médica, ambos os grupos pertencentes à uma Instituição de Ensino Superior do Estado de Minas Gerais.

A matéria complementar ofertou a possibilidade de protagonismo, flexibilidade e descentralização na formação médica com abordagem teórico-prática ${ }^{15,25}$. Das 120 horas teóricas, foi gerada a partilha e produção coletiva do conhecimento, com debates, aulas expositivas e abordagens ativas de ensino e aprendizagem. No primeiro momento, o foco estava direcionado para a compreensão da oralidade enquanto saber e fazer do conhecimento $\operatorname{popular}^{26}$, além da revisão de conceitos básicos sobre saúde do campo, saúde familiar e medicina complementar. 
O segundo momento contemplou a prática, realizada de maneira vivencial, imersa na ludicidade pedagógica e crítica, entrevistas e dialógicas, identitárias e ancestrais, num projeto de comunidade antroposófica, que celebra a vida, pareando a teoria textual ao saber oral de identidade e memória ${ }^{22-24}$. Assim, os princípios observados na educação biocêntrica, dialógica freiriana e na psicologia comunitária, usaram como sumo o saber popular ausente das cátedras.

Foram escolhidas 35 famílias multietárias e plurirraciais, totalizando 142 pessoas, atendidas por uma Unidade de Saúde da Família situada em zona rural, onde a prática da oralidade manifesta-se com maior facilidade e determinados ritos populares e tradicionais mantêm-se ativos e operantes no tecido $\operatorname{social}^{25,26}$ da microrregião. Concomitante à parte teórico-prática da matéria, um projeto de extensão fora criado, para que as atividades em contraturno pudessem ser reconhecidas como formação acadêmica complementar, assim, as famílias dispuseram de um calendário de atividade e atendimento mais funcional e coerente à demanda.

Os instrumentos didáticos da Pedagogia Griô ${ }^{23}$ foram utilizados para a criação de uma abordagem clínica formatada com a semiologia médica centrada nas narrativas interpessoais e construtoras da relação médico-paciente e paciente-médico. Dessa forma, a diagnose e a assistência terapêutica passaram por uma ressignificação baseada na historicidade e reflexo social do paciente assistido ${ }^{2,20}$.

A Pedagogia Griô, no Brasil idealizada por Lilian Pacheco ${ }^{23}$, é produto de um levante popular tradicional contra hegemônico, cujos alicerces estão na reivindicação da interdisciplinaridade do saber presente na tradição oral. Busca a unidade do pensamento democrático e o resgate de uma cultura comunal alicerçada no bem-estar coletivo, na qual "todo excluído da cultura hegemônica constrói sua cultura e seu espaço de inclusão, que se dá como cultura contra hegemônica" (PACHECO, 2006, p. 28). Fortalecendo a identidade do povo que 
busca a memória oral e o fortalecimento identitário, a Pedagogia Griô emerge na perspectiva decolonial.

A imersão, chave fundamental da intervenção apresentada, foi realizada para além dos muros da Unidade de Saúde, interligando a diversidade de fatores ao exercício reflexivo e narratológico partilhado nos preceitos de comunidade. As ligações, afetos e desafetos, anseios e mazelas das famílias foram acompanhadas de perto, tornando claro os efeitos do racismo na sociedade $^{18}$.

Portando, a metodologia adotada concentrou-se em atividades pedagógicas, acompanhamentos e atendimentos clínicos, visitas domiciliares, rodas de conversa e saber, imersão vivencial e empírica do cenário biopsicossocial da comunidade assistida pelo serviço de saúde ${ }^{8,10}$. O povo partilhou lugar de fala na sala de aula e os terreiros das casas tornaram-se espaços de danças, contações de causos e aprendizagem sobre as plantas, culinária e sistematização da sobrevivência com baixos recursos ${ }^{22}$.

\section{DESENVOLVIMENTO}

Nas últimas décadas acentuou-se na formação/prática da medicina baseada em evidências a pressão por parte da sociedade e dos movimentos em defesa dos Direitos Humanos, um posicionamento antirracista, capaz de promover reparação às divergências que o fazer clínico possa ter imprimido no tecido social, especificamente em comunidades carentes e grupos étnico raciais contra hegemônicos, como foi o caso dos negros, dos LGBTQIA+, dos povos indígenas e tantos outros povos em processo de dessilenciamento ${ }^{25}$.

A seguir, serão abordados os questionamentos norteadores das atividades realizadas a partir da oferta de educação e extensão universitária baseada no serviço e imersão em campo. É importante ressaltar que toda a construção textual exprime e registra as rodas de discussões e 
debates, as falas dos personagens nos cenários e toda a experiência captada durante os anos letivos de 2018-2019²6.

A problematização que se pretende fazer será responsável por detectar os pontos altos do racismo na sociedade e que implicam na formação/prática médica, bem como na relação do usuário com os serviços de saúde. Assim, o racismo passa a ter como resposta as práticas antirracistas, importantes para a obtenção dos produtos e resultados apresentados no decorrer do texto.

\section{Descontruindo a democracia racial no Brasil}

À priori, pode-se afirmar que existe uma discordância acirrada no tocante ao conceito de raça. Alguns autores afirmam que existe apenas uma raça, a raça humana, onde todos seriam iguais e sem distinções. Todavia, é pretensioso o discurso de igualdade racial para um país, como o Brasil, conforme veremos mais adiante, que extermina os povos não brancos de forma institucionalizada ${ }^{30}$.

Para se combater esse epistemicídio ${ }^{5}$ é preciso agir de forma antirracista, garantindo que as falas, memórias e direitos daqueles que vieram, daqueles que estão e daqueles que virão do seio da ancestralidade serão respeitados e terão seus respectivos lugares de fala garantidos ${ }^{4-5}$.

Dessa forma o mito de democracia racial $^{6}$ começa a ser derrubado, pois surgem povos e identidades que guardam as suas memórias comunais/coletivas e por isso sofrem a mais variada manifestação de marginalização ou racismo, independentemente de sua classe social ou poder aquisitivo, quando comparados ao povo branco.

O ser branco é a garantia de uma posição confortável e de segurança quando comparado ao não ser branco ${ }^{5}$. Isso significa dizer que afirmar uma identidade racial contrária à hegemônica é por si um ato de resistência política ${ }^{7,34}$, por isso arduamente atacada e silenciada, 
mas cujo efeito é dessilenciador e traz à luz a diversidade e o multiculturalismo que as práticas médicas necessitam para formular o fazer/ser médico antirracista.

A negligência que os demais grupos raciais sofrem na representatividade é calcada na supremacia estética e intelectual que o grupo etnocêntrico ocupa, mas cuja resistência dos demais grupos tem abalado em diversos setores, sendo um dos alvos os sistemas de saúde, a formação médica e principalmente a equidade que o Sistema Único de Saúde promete a todos os cidadãos ${ }^{1,14,29}$.

Essa suposta supremacia intelectual e estética apresenta-se como uma segura zona de conforto para o grupo hegemônico quanto ao lugar de pertencimento e fala, servindo-lhe de escudo quando outros grupos raciais cobram a participação e comunhão dos espaços historicamente ocupados por uma única narrativa. Um exemplo claro são os cursos elitizados de graduação de medicina e de direito, que mesmo com as políticas de ações afirmativas, tornaram a presença de pessoas não brancas aval para o mito da meritocracia, validando a exceção como regra ${ }^{20}$.

Tende a ser banido do tecido social eurocentrista aquilo que foge ao padrão hegemônico. Quando não apropriado por um determinado grupo etnocêntrico, e nele ressignificado, como os aspectos religiosos, culinários e culturais, à exemplo Iemanjá, deusa africana responsável por auxiliar na criação do homem, segundo as crenças africanistas, e retratada como mulher branca de olhos azuis ${ }^{4}$ o aspecto de contra cultura branca é rapidamente exterminado, pois "o que é hegemônico aceita apenas o que não lhe afeta tanto, o que afinal não é 'tão diferente assim'” (CAPUTO, 2012, p. 230).

A democracia racial não se resumiu somente ao processo de miscigenação, mas à todas as estruturas do poder econômico e do acesso aos saberes e fazeres científicos. Acerca da miscigenação, uma das bases do mito de democracia racial, cabe ressaltar que o sociólogo Gilberto Freyre a defendeu como um sucesso absoluto, todavia, eximiu-se dos efeitos colaterais, 
como o silenciamento étnico racial e a manutenção do processo de epistemicídio ${ }^{5}$ em curso, desde a chegada dos portugueses no Brasil.

A mistura entre as raças ou grupos raciais foi romantizada como algo natural entre a proximidade afetuosa entre negros, indígenas e europeus colonizadores. Por anos este discurso serviu como máscara para acobertar as atrocidades cometidas em nome do crescimento, colonização e prospecção do Brasil, fazendo crer que sempre houve uma harmonia entre os grupos raciais $^{3-7}$.

Assim, o discurso de ódio de extremistas racistas no Brasil, que tenta figurar o mito da democracia racial como sendo justo e equânime das diferenças é o mesmo que camufla que a desigualdade socioeconômica que faz aumentar a nuvem de extensa nuvem de pobreza na América Latina ${ }^{1-9}$. Logo, é pertinente refletir que os aspectos de adoecimento estão intrinsicamente relacionados às questões socioeconômicas ${ }^{14}$.

Para que a medicina, no seu fazer e formar, possa descontruir o mito da democracia racial é necessário reconhecer e afirmar que em hipótese alguma a miscigenação racial e cultural no Brasil ocorrera de forma livre e espontânea, pois o papel do europeu colonizador, majoritariamente branco e detentor de força bélica e econômica ${ }^{30-32}$, não foi de convidar e sim de violentar a integridade física e cultural de um povo que jamais se silenciou ou aceitou passivamente tal condição $0^{5-6}$.

\section{Quem constrói e narra as memórias silenciadas?}

A memória é crucial para a manutenção da identidade, servindo como um instrumento poderoso de emancipação ou subalternação $0^{3,18}$. Se a memória de um povo condiciona a de outros povos, que não o que dela precisa para a construção identitária, é sinônimo que há opressão de um grupo sobre outro, e neste caso os aspectos socioculturais passam a ser narrados a partir da percepção criada a favor de uma única narrativa ${ }^{3,21}$. 
A forma como a memória é narrada representa diretamente a manutenção dos interesses e o status quo que o grupo dominante pretende manter sobre a história ${ }^{4}$. A medicina tem pactuado diretamente com o sequestro de memórias ao não se posicionar contra as classes que articulam desigualdades raciais entre os grupos étnico raciais, pois "tem se deixado levar pelos interesses imperialistas do capitalismo instituído na grande indústria farmacêutica ou nas redes de hospitais particulares" (HELMAN, 2003, p.25).

Torna-se conveniente para determinado grupo que o que seja lembrado e preservado no presente o será de forma programada, um exemplo clássico é a forma como o colonialismo é propagado: um discurso heroico e desbravador, sendo que para os povos originários a colonização é encarada como invasão, sequestro e violentação. Duas narrativas completamente diferentes e cuja interpretação interfere diretamente na formação/prática médica ${ }^{34}$.

A interferência se dá quando o currículo, obtido a partir de uma narrativa unilateral e etnocêntrica, é construído e pensado com o saber e o fazer etnocêntrico. Os saberes passam por um filtro do interesse do mercado, da indústria da saúde e da própria classe médica, sendo marginalizado o saber popular, o saber oral e o não eurocentrista ${ }^{4-7}$.

Editar ou manipular a memória de um povo significa retirar dele o referencial do passado, a identidade comunal e o entendimento que o indivíduo possa ter o lugar de pertencimento, assim o presente está condicionado à incompreensão e o futuro da memória condicionado à historicidade do grupo etnocêntrico ${ }^{18,23}$.

Aquilo que se pretende explicitar é mais claro quando posto na prática das relações intergrupais. Ao observar a composição curricular do curso de graduação em medicina, bem como as etapas de pós-graduações, nota-se que todo o referencial teórico é majoritariamente composto por autores brancos, europeus ou norte-americanos ${ }^{2,7,29}$. E não é uma tendência sazonal, pelo contrário, é algo muito bem estruturado. 
À priori, a relevância acerca do debate e da narrativa da memória de determinados grupos tem sido colocada de lado, pois, desde a formação das primeiras turmas médicas no Brasil a representatividade tem sido tomada e dada por outros personagens, que não os detentores da identidade sequestrada, mas aqueles que, incansavelmente, ainda tomam proveito do etnocentrismo clássico ${ }^{24-25,29}$, pois “essa visão idílica, não realista e ao mesmo tempo autoritária sobre as relações raciais no Brasil foi muito útil para as elites do poder, sobretudo, nos momentos históricos em que o país viveu sob regimes ditatoriais” (GOMES, 2005, p.58).

Assim, é coerente afirmar que quem primeiro narra as memórias silenciadas são os livros didáticos, instrumento de (des)construção da memória de um povo no campo escolar, acadêmico e científico, e que passa a legitimar, por meio da tradição escritas e os seus registros, o apagamento dos rastros socioculturais que poderiam fomentar políticas públicas para a ação direta em saúde com um determinado grupo racial ${ }^{4-6,25-29}$.

A resistência que a memória individual e coletiva apresenta é um ato político, pois zela pela identidade do indivíduo inserido nas relações sociais e nas variadas formas de construção dos saberes ${ }^{17,26}$. Faz-se necessário manter longe da formação médica, ou de qualquer outra, as estruturas escravocratas, eurocentristas, reacionárias, preconceituosas e deturpadas da realidade, passando a adotar ações antirracistas.

Mas quem está narrando as memórias silenciadas? O mercado financeiro, estruturado no capitalismo desenfreado e excludente ${ }^{28}$. A formação acadêmica, hegemônica e eurocentrista, cujo saber é unilateral, restrito às narrativas dos saberes produzidos por um único grupo hegemônico, historicamente branco, detentor de poder bélico opressor e capital significativo ${ }^{6}$. A estrutura política, jurídica e religiosa, cuja falta de representatividade dos grupos étnico raciais realça as teias que o poder hegemônico detém, além da intolerância, afirmada com o crescimento dos discursos extremistas e totalitários, bem como a força que a teocracia tem tido nas bases do Estado de Direito ${ }^{6-7,16}$. 
Abordar o silenciamento das memórias é importante quando a medicina lida, também, com o corpo, elemento que perpassa a construção da memória e por ela é transpassada. O corpo é fragmento receptáculo da memória afetiva, comunal, participativa e cultural. Se ele é objeto de estudo da medicina, logo, a prática médica faz dele objeto de trabalho ${ }^{2}$.

A íntima ligação que há entre o corpo e a memória passa a ser nítida quando o primeiro é motivo de segregação. A forma como o corpo é lido e entendido é parte da narração da memória. Para melhor compreensão, quando, diante da epidemia de HIV/AIDS na década de 80/90, a parcela conservadora da sociedade, pós Segunda Guerra Mundial, não hesitou em associar o comportamento sociocultural dos homossexuais, a maneira como lidavam com o corpo e a sexualidade, ao surto de afetados pela $\operatorname{AIDS}^{14}$.

Dessa forma, a maneira como a memória, mesmo aquela do imaginário social conservador, interfere na relação da medicina com o corpo atendido, observado e afetado é, quando não inclusiva, excludente e racista, pois a perspectiva do médico, em formação ou atuação, está correlacionada diretamente à projeção das memórias no tecido social, ou seja, a forma como o comportamento do indivíduo é visto pelo grupo dominante é a mesma forma como o corpo é tratado na medicina.

Essa percepção racista que a prática clínica reforça é institucionalizada como uma plano genocida contra o povo preto $^{32,34}$, por exemplo, “ou seja, o que mudou foi a maneira como o racismo se manifesta, passando de um caráter explícito para uma configuração implícita à situações e contextos mais refinados de exclusão étnico-racial” (SOUZA, 2012, p. 34).

Expor o racismo, o preconceito e a discriminação racial é crucial para lutas e movimentos identitários multiculturais, que expressam resistência antirracista e constroem novas memórias, assumindo a narrativa da historicidade e identidade dos corpos e falas que até outrora eram silenciados, mas como será visto adiante, apresentam-se dessilenciados e tomados 
de empoderamento, autoconhecimento e lugar de pertencimento. A memória sequestrada está sendo retomada por seus narradores originais ${ }^{5}$.

\section{A posição da formação e prática médica diante do racismo, preconceito $e$} discriminação

O etnocêntrico, também chamado aqui de grupo dominante, é reconhecido por hipervalorizar a sua própria cultura e valores éticos e morais, sendo que nem sempre o seu interesse está centrado na eliminação do outro grupo, mas sim na transformação ou conversão da gama de aspectos que determinam diferenças e identidades entre ambos.

Assim, é necessário entender que a "racialidade no Brasil determina que o processo saúde-doença-morte apresente características distintas para cada um dos seus vetores”, assim a dinâmica tem afetado as memórias, corpos e falas numa percepção macro, iniciada na educação/formação, escolar ou universitária, e que reflete na prática e assinala que a "branquitude e negritude detêm condicionantes diferenciados quanto ao viver e o morrer" (CARNEIRO, 2005, p.77).

Afirmou-se anteriormente que o racismo é estrutural e que as suas raízes estão espalhadas de forma multisetorial, afetando com variabilidade os grupos contrários à norma etnocêntrica ${ }^{15,24}$. Como o racismo está estruturado na formação/prática médica? O currículo é pensado para atender a todos os grupos étnico raciais? Se tais questionamentos inquietam, podese afirmar que a zona de conforto está sendo quebrada e a discussão até aqui está surtindo efeito.

As ações afirmativas permitiram a presença de outros saberes e fazeres, como a elaboração e oferta de práticas pedagógicas descentralizadas da formalidade erudita das cátedras, na formação das grandes áreas da saúde. Cursos historicamente formados por, na sua maioria, homens brancos e de classe média/alta, passaram a contar narrativas antirracistas, mas mesmo com todo o esforço e luta para a ocupação dos espaços acadêmicos, o que se vê é uma 
exceção à regra, onde indígenas, quilombolas, negros e periféricos são postos como prova da eficácia da meritocracia ${ }^{5}$.

Ora, o racismo apresenta-se inicialmente antes mesmo da formação multidisciplinar em saúde. Ocupar uma vaga no curso de medicina e não corresponder ao padrão historicamente estabelecido, garante ao futuro médico o título de herói, e de fato não deixa de sê-lo. Mas observar como a Universidade lida com a diversidade dos corpos e identidades é marcador para desvelar o racismo estrutural e que reflete no mercado/prática profissional.

O estudante passa a ser universitário após um processo excludente e discriminatório, que em nada observa as dessemelhanças biopsicossociais dos candidatos. Reproduz, inúmeras vezes, comportamentos característicos do machismo, misoginia, racismo e preconceitos. E por fim, leva para a prática o adoecimento social que o currículo não se atentou em mitigar e prevenir, ou reduzir, os danos, tento apenas absorvido e perpetuado o processo engendrado e retornado à sociedade, transformando a formação em uma das bases do ciclo silenciador dos grupos minoritários ${ }^{19}$.

A prática é diretamente afetada pela formação, na graduação ou na especialização, e pouco pactua com os movimentos e demandas sociais. Ensaia uma aproximação com a defesa do SUS, quando se trata de uma IES pública, mas pouco se conecta às demandas sociais e raciais $^{20,28}$.

Este comportamento, oscilante e desinteressado, não é exclusivo da medicina, sendo notado em outras graduações, mas muito mais marcante no curso mais concorrido do Brasil e, cuja atuação é de extrema relevância para a sociedade. Como romper com o comportamento passivo do saber e fazer médico diante do racismo? A quem interessa a inercia de uma das maiores e mais importantes classes profissionais do Brasil $?^{20}$ 
É preciso refletir. O mercado, que pelo capitalismo alimenta e nutri a desigualdade socioeconômica no Brasil tem lucro real? Ou seria o Estado implantando uma política higienista e eugênica, utilizando-se dos serviços de saúde? Por qual razão incomoda tanto a presença de negros, indígenas e outros povos nos lugares furtados e protegidos pela elite branca? Seria pretencioso redigir uma única resposta. É mais enriquecedor abrir o debate e provocar a inquietação, e assim promover uma discussão saudável para todos os grupos, sem exceção ${ }^{20,28-}$ 32.

A posição da formação/prática médica ainda se mantém passiva diante do racismo. A afirmação é resultado de constatações alarmantes, como o recorte da população negra brasileira, que depende majoritariamente do serviço público de saúde, dele sendo vítima, sendo que a mulher negra permanece como alvo das inúmeras contravenções do sistema e agentes de saúde. São elas, mulheres negras que sofrem mais violência obstetra, têm acesso escasso aos exames como mamografia e menor tempo de consulta. Entender a lógica daquilo que se está afirmando é observar quem compõem a maior parte da base proletária/operária do Brasil, ou, ainda, quem tem sofrido ataques contínuos à título do crescimento agropecuário, como tem ocorrido com os indígenas ${ }^{5,12-14,18}$.

A luta antirracista exige posicionamento dos personagens e cenários ${ }^{18}$. Fortalecer os movimentos que estão surgindo, ou que já existem, como os coletivos, as ações afirmativas, a produção cientifica, as referências aos fazeres e saberes multidisciplinares, os aspectos culturais, a diversidade religiosa e tantos outros elementos, é um dispositivo de blindagem que todos podem construir à favor dos grupos em dessilenciamento ${ }^{17}$. A medicina pode, em sua maioria, estar passiva e inerte, mas estruturas tradicionais começam a sofrer impactos significativos e mudanças já podem ser sentidas ${ }^{15}$.

Graças às políticas de ações afirmativas ${ }^{1,5-6}$, o multiculturalismo tem ganhado espaço crescente na formação médica brasileira, impactando positivamente a formação/prática médica 
nacional, reforçando que "na verdade, toda mudança transformadora, toda revolução ocorre no interior de uma tradição, seja para recusar o negativo, seja para retomar o livre fluxo das forças necessárias à continuidade do grupo.” (CAPUTO, 2012. p.118).

\section{O dessilenciamento e o resgate identitário que a medicina pode fomentar}

O dessilenciamento étnico-racial é possibilitado pela participação democrática e cidadã nos variados espaços da sociedade, como nas escolas médicas, que por meio de projetos voltados para a comunidade circunvizinha, abraça a diversidade e torna-se lugar de fala daquelas(es) que em outros momentos/lugares têm seus saberes inferiorizados ${ }^{5,18-19}$.

A ideia de silêncio precisa ser melhor entendida. Há o silêncio forçado, imposto e violento, fruto do sequestro do Estado de Direito, da ausência gélida da liberdade constitucional e garantida pela democracia. Contraposto ao silêncio imposto, há o silêncio voluntário, que está presente nas manifestações culturais e religiosas, nos segredos comunais passados de pai para filho, de avó para neta ${ }^{34}$.

A diferença entre o silêncio forçado, resultado de violações dos direitos básicos de um ser humano e o silêncio voluntário, traçado a partir do interesse coletivo de determinado grupo, reside justamente nos produtos que ambos geram. O primeiro resulta na fragmentação da identidade e o segundo justamente no fortalecimento. Logo, é coerente afirmar que o processo de dessilenciamento é multissetorial e bilateral, sendo o perfeito encontro entre as ações antirracistas e as de resistência ${ }^{5,34}$.

O dessilenciamento que a prática médica pode fomentar é iniciado na formação, ainda na graduação, dando visibilidade aos inúmeros instrumentos e mecanismos antirracistas, como os coletivos, os eventos científicos e pontualmente alterações curriculares, responsáveis por mudanças sociocomportamentais, pois o "seu objeto é a mudança da narrativa histórica, se lhe 
faltar o referencial do passado, o presente permanece incompreensível e o futuro escapa a qualquer projeto" (MENESES, 1992, p.14).

O processo de dessilenciamento é iniciado pelo resgate das narrativas e memórias. O lugar de fala passa a ser partilhado, tornando-se um bem comum dos múltiplos fazeres e saberes. A oralidade, marca identitária de muitos povos e grupos, passa a compor a formação médica e contribuir com o surgimento de um currículo informal e complementar ${ }^{20-23}$.

\section{RESULTADOS E DISCUSSÕES}

Dentre os produtos que as tensões entre os grupos e classes sociais imprimem na formação e (des)construção identitária médica e dos povos não-brancos, nota-se o movimento articular-intersetorial-antirracista.

Este trabalho é parte do produto disponibilizado pela criação e oferta de uma intervenção pedagógica. Inicialmente ofertada para 45 alunos, a disciplina optativa apresentou uma lista de espera com mais de 110 acadêmicos interessados na oferta, demonstrando que há interesse na formação antirracista.

O processo de criação e planejamento pedagógico apresentou resistência política e institucional, visto que inúmeros pontos da ementa da matéria foram questionados, como a abordagem ao feminismo negro, às religiões não cristãs ${ }^{31}$ e às práticas que envolviam dança, corporeidade e musicalidade como resgate da oralidade ${ }^{2,22}$. O que pode ser percebido foi o processo de higienização racial que o docente é submetido à título de padronização curricular ${ }^{4}$.

Todo o conteúdo desenvolvido e ministrado teve por objetivo a formação humanizada e autocritica de médicos, além de possibilitar transformações nos cenários da prática clínica e ambulatorial, que também apresentou significativa resistência, pois, como afirmaram alguns docentes, durante oficinais realizadas e nas rodas de conversa teórico-práticas, do ciclo clínico e internado "não se pode querer reinventar a roda". 
O mesmo pode ser percebido em constantes feedbacks e reclamações à coordenação de graduação do curso de medicina, onde foi relata a insatisfação de um grupo significativo de docentes, e evidenciada na devolutiva dos formulários de participação das atividades em campo e acompanhadas por docentes de outras matérias. Tal comportamento já era aguardado, visto que "pensar na lógica da oralidade, implica desafiar séculos de dominação etnocêntrica e reinventar a roda" (PACHECO, 2006, p.29).

Da oferta da matéria, obteve-se a produção de um documento apresentando demandas relatadas pela comunidade acadêmica discente. Além disso, a ampla produção textual foi possibilitada, deixando registrado a necessidade de formulação de políticas e ações pedagógicas permanentes na formação médica/prática médica.

A experiência obtida alinha-se com o desejo de reparação, equiparação e equalização que os movimentos sociais cobram como políticas públicas do Estado. O epistemicídio ${ }^{5}$ praticado pelo silenciamento racial passou a ser brecado por conta das intervenções antirracistas. Todo o layout de atendimento e acolhimento durante a consulta médica foi repensado no intuito de tornar o ambiente aberto para a diversidade cultural da região estudada, sendo esse um dos fatores de redução das faltas às consultas e palestras educativas ${ }^{2,20}$.

A forma como o exame físico era realizado tendia à inibição, constrangimento e resistência por parte da população. Com a imersão na comunidade, no rito da alimentação, da colheita e da intimidade das casas, os pacientes passaram a pedir, e até mesmo exigir, o exame físico. A barreira que o distanciamento socio acadêmico impunha na relação do serviço/equipe de saúde com os usuários foi ressignificada ao passo de surgirem laços afetivos, humanizando o atendimento e tornando linear os saberes e conhecimentos medicinais, formais e informais ${ }^{2}$.

O aumento na adesão terapêutica medicamentosa só pode ser notado graças à adesão, por parte dos médicos, de medicação homeoterápica, que associada à farmacologia tradicional, 
reduziu o índice de pacientes diabéticos, hipertensos e dislipidêmicos descompensados. $\mathrm{O}$ mesmo ocorreu com a dieta nutritiva, cujo trabalho interdisciplinar, com a presença de nutricionistas da rede estadual de saúde, deu voz às crenças, às liturgias e ao sagrado que repousa na alimentação popular ${ }^{4,23,34}$.

Os resultados antirracistas foram bem além da semiologia. A educação em saúde apresentou-se significativa quando duas parteiras foram apresentadas à equipe de saúde. Sozinha, uma das parteiras havia realizado mais de 24 partos nos últimos 5 anos. Entender a cultura do parto realizado por parteiras foi crucial para a redução da natalidade e o estímulo às gestantes para o acompanhamento neonatal completo. Além disso, as parteiras puderam aprender técnicas, visando a redução de erros na hora dos partos, bem como ensinar e compartilhar as práticas que elas herdaram das suas bisavós ${ }^{14,33}$.

Os homens, dados ao trabalho braçal intenso e cansativo, muito pouco utilizavam os serviços de saúde, e dele apresentavam críticas e preconceitos, fato decorrente da posição de distanciamento que a medicina adotou em detrimento da população ${ }^{25}$. Na região havia uma alta incidência de câncer de pele entre os homens, que passavam horas expostos ao sol e sem qualquer proteção. A intervenção nesse aspecto envolveu as mulheres, que realizavam trabalhos artesanais com matéria prima natural, como palha, folha de bananeiras etc. Sombreiros foram feitos por elas e distribuídos a todos os trabalhados e trabalhadoras, acompanhados de protetor solar.

Não se imaginava que o estreitamento das relações entre os grupos, médicos e população, resultasse em ótimos indicadores, como foi o caso com o alcoolismo. Por produzirem cachaça artesanal, muitos homens apresentavam um quadro de dependência química e eram resistentes a quaisquer intervenções médica ou psicológicas ${ }^{25}$. Foi com o apoio do padre e da igreja local que intervenções multisetoriais foram feitas. 
Na região há uma festa anual dedicada à Nossa Senhora das Candeias, um evento grande e que envolve não só a região assistida, mas cidades vizinhas. Mais de $90 \%$ das famílias estudas são católicas e praticantes, tendo a igreja como pilar institucional na relação familiar. E foi justamente essa influência que favoreceu a entrada das equipes de saúde nos $\operatorname{lares}^{22-23}$ com algum dependente químico. Eliminar do dia para a noite a ingestão de álcool não foi possível, mas reduzir os danos por ele causado $\operatorname{sim}^{29}$.

Os danos causados pela bebida alcoólica refletiam diretamente nos índices de violência doméstica, inúmeras mulheres achavam natural que os homens fossem agressivos ${ }^{19}$, e, com muita intervenção e presença constante dos estudantes e profissionais da saúde, pode-se afirmar que das 35 famílias, $82 \%$ não relatou violência doméstica durante as atividades práticas oferecidas.

Os casos de gravidez na adolescência e evasão escolar também reduziram. Ações foram realizadas na única escola da região e visaram educar acerca da sexualidade e higiene íntima. A saúde bucal ganhou visibilidade com a notícia da filmagem da Festa de Nossa Senhora das Candeias, fazendo aumentar significativamente a buscar por dentistas que atuavam na área, principalmente quando se anunciou o concurso para Rei e Rainha da Festa, cuja premiação seria um álbum de fotos profissionais e uma leitoa, doada por um dos moradores.

A espiritualidade afirmou-se como forte aliada na construção de sentimentos coletivos. Aspectos culturais e diretamente ligados às práticas religiosas, como festas e novenas, até mesmo casamentos e velórios, serviram como espaço para intervenções médicas antirracistas. Ou seja, a prática médica adotou estratégias de redução de danos, visto que o cerne cultural, dentro das ações antirracistas, não pode sofrer alteração, pois passaria a legitimar um processo de higienização, como ocorreu no processo de colonização das Américas, onde os povos originários foram submetidos às mais variadas violências identitárias. 
A presença de outras áreas da saúde, como a enfermagem, possibilitou a praticidade da transmissão de saberes e do processo de ensino-serviço-aprendizagem. Crenças e costumes acerca de feridas, de determinadas doenças e patologias puderam conflitar harmoniosamente com os saberes científicos. A medicina popular, feita na alquimia das cozinhas dos lares mais humildes, recebeu suporte da medicina farmacológica e subsidiada pelas pesquisas e investigações laboratoriais.

Assim, resultados e produtos foram notados, dando mérito às práticas antirracistas, que não permitiram o preconceito racial e social, que mostraram as belezas do multiculturalismo ${ }^{4} \mathrm{e}$ enriqueceram o currículo até mesmo daqueles que já estavam atuando na região há anos. Foram 11 meses de intensas atividades e inúmeras intervenções educacionais de empoderamento, dando aos participantes a dimensão das raízes racistas e por consequente as formas de destruílas ${ }^{5}$

Quando a patologia deixa de ser o foco da intervenção clínica, é possível que esses e outros resultados sejam apontados em abundância. Não é utopia ou sensacionalismo, é prática. Acadêmicos e médicos em atuação estão cada vez mais isolados em seus ambulatórios e na posição passiva-ativa do atendimento. Inverter a ordem lógica do serviço de saúde é uma das táticas mais eficientes para a promoção, universalização e equidade da oferta de saúde pública.

Todas as práticas foram custeadas pelo Estado, mas não como assistencialismo, apenas um bom cumprimento da legislação existente, como a ampla legislação do Sistema Único de Saúde. Logo, é preciso que haja reflexão crítica sobre o ensino do direito em saúde, previsto na Carta Magna de 1988 e inquestionável no Estado de Direito, como é o Brasil.

De nada adianta as salas dos cursos de medicina estarem abarrotadas de estudantes e estes não devolverem para a sociedade os saberes, em muitos casos, financiados por cada cidadão contribuinte. Assim, a educação-serviço é um aperfeiçoamento na formação e na 
prática médica, ao mesmo passo que representa a luta por acesso e oferta de saúde às populações marginalizadas e em situação de vulnerabilidade socioeconômica. É preciso que o curso de graduação em medicina e, tantos outros cursos da área da saúde, retomem o papel de resistência, luta e aquisição de direitos para os pobres e oprimidos brasileiros, sem romantismo ou discurso ideológico, mas apenas por entender que o fazer médico é instrumento assegurador do direito à vida.

Enquanto o saber médico se manter isolado nas cátedras universitárias, pessoas morrem sem o direito ao acesso do olhar clínico, privadas de qualidade e imersas na invisibilidade social. Políticas existem, mas enquanto estiverem pareadas com a desigualdade social, não surtirão os efeitos esperados e necessários. A pobreza permanece sendo uma patologia crônica e que apresenta comorbidades cada vez mais agudas e deletérias. Quebrar o ciclo existente de miséria e extrema pobreza é dever de todos que acreditam em um Brasil melhor, patriota e livre da separação ideológica, da violência institucionalizada por governos e reproduzida por grupos étnico raciais.

\section{CONCLUSÕES}

A Pedagogia Griô ${ }^{22}$ é uma ferramenta de dessilenciamento e construção da autoimagem dos povos em dessilenciamento, que passam a usufruir da equalização e reparação social ${ }^{28}$. A ancestralidade, nesse contexto, colabora com a solidificação de novos saberes, dando espaço de fala aos povos tradicionais, reconectando com os saberes comunais e ancestres. A experiência descrita empodera a memória, se ocupa de dar voz à medicina popular e a se impor como instrumento antirracista ${ }^{30}$.

Os resultados apresentados foram significantes para a formação/prática médica, mas também obtiveram destaque entre a comunidade, que passou a utilizar o serviço de saúde como promotora de saúde e laços afetivos, excluindo do imaginários social os falsos paradigmas e dogmas acerca dos profissionais do serviço, em destaque a figura do médico ${ }^{20}$. 
As ações antirracistas são apresentadas na literatura com alto grau de complexidade teórica e de compreensão e análises densas. Porém, todas as intervenções realizadas foram consagras pelo êxito quando se despiram das normas científicas e dos inúmeros protocolos da educação e da saúde, adotando a vivência, permitindo o ser afetado e o $\operatorname{afetar}^{22}$.

Por fim, o processo de dessilenciamento de grupos étnico raciais é parte de ações coletivas de empoderamento e conscientização. Para que um personagem/cenário possa ser afetado por intervenções antirracistas é preciso, primeiro, descontruir o saber baseado no epistemicídio $^{5}$ e compartilhar os locais de fala, permitindo a auto narrativa da historicidade identitária $^{12}$ que resultará na promoção da saúde, na redução de danos e formação/prática médica humanizada.

\section{REFERÊNCIAS BIBLIOGRÁFICAS}

1. ALBUQUERQUE, V.S. et al. A integração ensino-serviço no contexto dos processos de mudança na formação superior dos profissionais de saúde. Rev. Bras. Educ. Med., v.32, n.3, p.356-62, 2008.

2. ANDRADE, J. T. Medicina alternativa e complementar: experiência, corporeidade e transformação. Salvador: UFBA; Fortaleza: EdUECE, 2006.

3. BARROSO, M. V.; BARROSO, M. H. . História oral, Memória e Cidadania. In: COSTA, C. B.; LONGO, C. A.; BARROSO, E. p. (Org.). História Oral e Metodologia de Pesquisa em História: Objetos, Abordagens, Temáticas. $1^{\mathrm{a}}$ ed. São Paulo: Paco Editorial, 2016, v. 01, cap.7, p. 151-168.

4. CAPUTO, S. G. Educação nos terreiros: e como a escola se relaciona com crianças de Candomblé. Rio de Janeiro: Pallas, 2012.

5. CARNEIRO, A. S. A construção do outro como não-ser como fundamento do ser. 2005. 339 f. Tese (Doutorado em Filosofia) - Faculdade de Educação, Universidade de São Paulo, São Paulo, 2005. Disponível em:〈http://bdpi.us p.br/single.php?_id=001465832〉.

6. CAVALLEIRO, E. dos S. Introdução. In: HENRIQUES, Ricardo (Org.). Educação antiracista: caminhos abertos pela Lei Federal no 10.639/03. Brasília: Ministério da Educação, Secretaria de Educação Continuada, Alfabetização e Diversidade (MEC/SECAD), 2005, p. 11-18. 
7. CÉSAIRE, A. Discurso sobre o colonialismo. Tradução de Anísio Garcez Homem. Ed. Letras Contemporâneas, 2010.

8. DENZIN, N.; LINCOLN, Y. O planejamento da pesquisa qualitativa: teorias e abordagens. Porto Alegre: Artmed, 2006.

9. FORQUIN, J.-C. Escola e Cultura - as bases sociais epistemológicas do conhecimento escolar. Porto Alegre: Artes Médicas, 1993.

10. GERHARDT, T. E.; SILVEIRA, D. T. (Org.). Métodos de Pesquisa. 1. ed. Porto Alegre: Editora da UFRGS, 2009. v. 1. p. 31-43.

11. GIL, A. C. Como elaborar projetos de pesquisa. 4. ed. São Paulo: Atlas, 2002, p. 59-81.

12. GOMES, N. L. Alguns termos e conceitos presentes no debate sobre relações raciais no Brasil: uma breve discussão. In: HENRIQUES, Ricardo (Org.). Educação antirracista: caminhos abertos pela Lei Federal n 10.639/03. Brasília: Ministério da Educação, Secretaria de Educação Continuada, Alfabetização e Diversidade (MEC/SECAD), 2005, p. 39-62.

13. HAMPÂTÉ BÂ, A. A Tradição Viva. In: KI-ZERBO, J. (org.). História Geral da África: Metodologia e pré-história da África. Vol. I. São Paulo: Ática/Unesco, 2010. p.222-267.

14. HELMAN, C. G. Cultura, saúde e doença. Porto Alegre: Artmed, 2003.

15. LIMA, D.M.S. ; SOUSA, C. A. M. . Educação em Direitos Humanos: Olhares sobre a efetividade da Lei Federal nº 10.639/2003. In: Geraldo Caliman. (Org.). Violências e Direitos Humanos: espaços da educação. $1^{\text {a }}$ ed. Brasília: Liber Livro, 2013, p. 145-161.

16. LA BOÉTIE, É. de. Discurso da Servidão Voluntária. Tradução de Casemiro Linarth. São Paulo: Martin Claret, 2009, p.7-74.

17. MACHADO, A. F. Linguagem e Identidade Africana/Afro-brasileira. Revista de Letras. Vitória da Conquista, v.3 n.2 p.201-219, jul./dez. 2011.

18. MENESES, U. T. B. de. A História, Cativa da Memória? Para um Mapeamento da Memória no Campo das Ciências Sociais. Revista do Instituto de Estudos Brasileiros, São Paulo, nº. 34, p. 9-23, 1992. ISSN 2316-901X. Disponível em: <http://www.revistas.us p.br/rieb/article/view/70497>.

19. NASCIMENTO, A. do. Quilombismo. Vozes: Petrópolis, 1980.

20. OLIVEIRA, F. R. Q. As Santas Quebradas: violência contra a mulher pela voz das vítimas. Goiânia: Ed. da PUC Goiás, 2010.

21. OLIVEIRA, R. Z.; GONCALVES, M. B.; BELLINI, L. M. Acadêmicos de medicina e suas concepções sobre "ser médico". Rev. bras. educ. med., Rio de Janeiro, v. 35, n. 3, p. 311-318, $2011 . \quad$ Set. Disponível em: 
<http://www.scielo.br/scielo.php?script=sci_arttext\&pid=S0100-

$55022011000300003 \& \operatorname{lng}=\mathrm{en} \& \mathrm{nrm}=\mathrm{iso}>$.

22. ORWELL, G. A revolução dos bichos: um conto de fadas. Tradução de Heitor Aquino Ferreira; posfácio de Christopher Hitchens. São Paulo: Companhia das Letras, 2007.

23. PACHECO, L. Pedagogia griô: a reinvenção da roda da vida. $1^{\mathrm{a}}$ ed. Lençóis: Grãos de Luz e Griô, 2006.

24. PÓVOAS, R. do C. A memória do feminino no candomblé: tecelagem e padronização do tecido social do povo de terreiro. Ilhéus: Editus, 2010.

25. ROCHA, A. M. A exclusão intelectual do pensamento negro. Pólemos. Brasília, vol. 2, n. 4, março 2014. Disponível em: <http://periodicos.unb.br/index.php/polemos/issue/view/975/showToc>.

26. ROSENO, S. M. Educação do Campo: Pedagogia em Lócus de Resistência. In: I Encontro de pesquisas e práticas em Educação do Campo da Paraíba, 2011, João Pessoa. Disponível em:<http://www.ieppecpb2011.xpg.com.br/conteudo/Gts/GT\%20-\%2001/14.pdf>.

27. SANTOS, J. A. A oralidade como meio de preservação da identidade afro-brasileira. In: MARTINS, Dimas (Org.) et al. Diversidade e convivência: vencendo desafios. Salvador: EDUFBA, 2009, p.95-116.

28. SANTOS, S. A. dos. A Lei $n^{\circ} 10.639 / 03$ como fruto da luta antirracista do Movimento Negro In: HENRIQUES, Ricardo (Org.). Educação antirracista: caminhos abertos pela Lei Federal $n^{o}$ 10.639/03. Brasília: Ministério da Educação, Secretaria de Educação Continuada, Alfabetização e Diversidade (MEC/SECAD), 2005, p. 21-37.

29. SCHRAIBER, L. Educação médica e capitalismo: um estudo das relações educação e prática médica na ordem social capitalista. São Paulo: Hucitec, 1989.

30. SILVA JUNIOR, A.G. Modelos assistenciais em saúde: o debate no campo da Saúde Coletiva. São Paulo: Hucitec, 1998.

31. SILVA-REIS, D.S.; ARAÚJO, C.G.S. Tradução e diáspora negra: entre decolonialismo e antirracismo. In: V Semana de Reflexões sobre Negritude, Gênero e Raça. Decolonidade e Antirracismo, 2015. V SERNEGRA - Semana de Reflexões sobre Negritude, Gênero e Raça: Caderno de Resumos. FEIJÓ,G. V.; MARTINS, P. R. A. (orgs.). Brasília: Editora do IFB, 2016. p. 44-52.

32. SILVA, N. F. I. Africanidade e Religiosidade: Uma Possibilidade de Abordagem sobre as Sagradas Matrizes Africanas na Escola. In: HENRIQUES, Ricardo (Org.). Educação antirracista: caminhos abertos pela Lei Federal no 10.639/03. Brasília: Ministério da 
Educação, Secretaria de Educação Continuada, Alfabetização e Diversidade (MEC/SECAD), 2005, p. 121-130.

33. SOUSA, F. M. do N. Linguagens Escolas e Reprodução do Preconceito. In: HENRIQUES, Ricardo (Org.). Educação antirracista: caminhos abertos pela Lei Federal no 10.639/03. Brasília: Ministério da Educação, Secretaria de Educação Continuada, Alfabetização e Diversidade (MEC/SECAD), 2005, p. 105-120.

34. SOUZA, G.S. Um olhar a partir de vozes historicamente silenciadas. In: III ENCONTRO BAIANO DE ESTUDOS EM CULTURA, Cachoeira, Recôncavo da Bahia, abril de 2012. Disponível em: <http://www3.ufrb.edu.br/ebecult/wp-content/uploads/2012/05/Um-olhar-apartir-de-vozes-historicamente-silenciadas-.pdf>.

35. VERGER, P. F. Os Libertos. Salvador: Corrupio, 1992. 